\title{
EDUCAÇÃO AMBIENTAL NA ESCOLA E NO PARQUE: EXPERIÊNCIAS COM O ARCO DE MAGUEREZ NA EDUCAÇÃO BÁSICA
}

Érika Cristina Teixeira dos Anjos Brandão ${ }^{1}$

Sindiany Suelen Caduda dos Santos ${ }^{2}$

Resumo: $O$ artigo analisou a relação socioambiental entre alunos(as) do $6^{\circ}$ ano, de uma escola municipal da Grande Aracaju, e o Parque Natural Municipal do Poxim (PNMP), por meio da metodologia da problematização. Através da investigação-ação-participativa, os dados foram observados sistematicamente durante as etapas: observação da realidade, seleção dos pontos-chave, teorização, hipóteses de solução e aplicação à realidade. $O$ trabalho evidencia o protagonismo dos(as) estudantes, especialmente durante a elaboração e entrega de uma carta de intenção para os gestores públicos de Aracaju, em favor da proteção do Parque. A pesquisa revela as potencialidades do uso de Metodologias Ativas para trabalhar a Educação Ambiental Crítica nas escolas.

Palavras-chave: Metodologias Ativas; Parque Natural Municipal do Poxim; Ensino em Espaço Formal e Não-formal; Sergipe.

Abstract: The article analyzed the socio-environmental relation between $6^{\text {th }}$ grade students from a municipal school in Aracaju metropolitan area, and the Poxim Municipal Natural Park (PNMP), using the problematization methodology. Through participatory action research, data were systematically observed during the steps: observation of reality, selection of key points, theorization, hypotheses of solution and application to reality. The work highlights the role of students, especially during the preparation and delivery of a letter of intent to public managers in Aracaju, in favor of protecting the Park. The research reveals the potential of using Active Methodologies to work on Critical Environmental Education in schools.

Keywords: Active Methodologies; Poxim Municipal Natural Park; Teaching at Formal and Non-Formal Spaces; Sergipe (Brazil).

${ }^{1}$ Instituto Federal de Sergipe (IFS). E-mail: erikaanjosbrandao@gmail.com. Link para o Lattes: http://lattes.cnpq.br/2024806911887716

2Universidade Federal de Sergipe (UFS). E-mail: sindianyscs@gmail.com. Link para o Lattes: http://lattes.cnpq.br/1099852783348463

Revbea, São Paulo, v.16, № 1: 410-429, 2021. 


\section{Introdução}

A escola, como um ambiente de formação de cidadãos reflexivos e críticos, tem um papel fundamental na construção de uma relação equilibrada entre natureza e sociedade (CARVALHO, 2012). Em meio ao papel relevante do professor no processo de ensino e aprendizagem, cabe a este elaborar abordagens teórico-metodológicas que contrastem com a ideia das metodologias tradicionais (MORAN, 2015), valorizando o ensino formal que acontece na escola e o não-formal, sem dissociá-los.

Dentre os ambientes não-formais de ensino estão incluídos: teatro, parque, rua, praça, terreno, praia etc. (MARANDINO et al., 2003). Os Parques Naturais, Áreas Protegidas por meio de Decretos federais, municipais ou estaduais, são espaços territorialmente demarcados cuja principal função é a conservação e/ou a preservação de recursos, naturais e/ou culturais a ela associados (BRASIL, 2011); o que os torna ambientes para desenvolvimento da Educação Ambiental (EA).

Ao considerar os Parques naturais como ambientes importantes de educação não-formal, Rempel et al. (2008) observaram que: a distância da escola interfere na conservação da Floresta Nacional de Canela (RS) e ações antrópicas neste local não influenciam significativamente na vida da comunidade escolar quando estão localizadas mais distantes da Floresta. No entanto, quando os(as) alunos(as) das escolas mais distantes foram levados a observar com maior proximidade o ambiente natural, suas atitudes e valores frente às Unidades de Conservação (UC) foram modificados.

É papel da EA sensibilizar os cidadãos para a importância do local onde vivem e valorizar sua história, riqueza e diversidade cultural (CARVALHO, 2012). Para isso, a Educação Ambiental na escola deve promover a integração entre o aluno(a) e o ambiente em seu entorno. A EA está diretamente correlacionada com a reflexão acerca do conhecimento científico vinculado aos saberes da realidade cotidiana dos(as) alunos(as).

Dito isso, esta pesquisa partiu da necessidade de investigar as relações existentes entre os(as) estudantes de uma escola pública de Aracaju situada nas proximidades do Parque Natural Municipal do Poxim (PNMP) instituído por Lei municipal (Decreto no 5370, de agosto de 2016) e o próprio Parque. No entorno do PNMP está situado o Rio Poxim, um manancial, pertencente à subbacia hidrográfica do Rio Sergipe que serve de suporte para o consumo humano e animal, para irrigação em propriedades rurais e para uso industrial. Apesar de sua importância socioeconômica, o rio encontra-se em alto estado de degradação ambiental, no que se refere à supressão de sua vegetação ciliar, nos focos de lixo doméstico, erosão, desmatamento e lançamento in natura de efluentes domésticos e industriais (FERREIRA et al., 2011; SANTOS; SOUZA, 2015).

Nesse sentido, ao trabalhar com esse ambiente de influência antrópica e que ao mesmo tempo pertence a uma Unidade de Conservação em ambiente 
urbano, é possível explorar o conhecimento e a visão dos(as) alunos(as) frente às questões ambientais que interferem diretamente nas suas vidas e na relação com o ambiente natural da UC (SCHRÖETTER, 2015), desencadeando tomada de decisões e transformação dos sujeitos.

A práxis da EA crítica está voltada à perspectiva participativa capaz de funcionar como fonte de informações e posterior elaboração de ações voltadas para busca de soluções coletivas diante dos problemas socioambientais (NEPOMUCENO, 2018). A EA deve estar voltada para a transformação social, levando em conta que os recursos naturais se esgotam e o principal responsável pela degradação da natureza é o ser humano (JACOBI, 2003).

Nessa direção, as metodologias ativas constituem ponto de partida relevantes para a abordagem da EA crítica nas escolas e nos espaços nãoformais de ensino. $O$ uso das metodologias ativas tem o potencial de despertar a curiosidade, pois os(as) alunos(as), ao pesquisarem e descobrirem realidades diferentes das quais estão acostumados, sentem-se motivados a buscar soluções para a sua realidade local (MORAN, 2015). Dessa forma, a problematização, através do Método do Arco, de Charles Maguerez, pode ser utilizada como um caminho para o ensino e aprendizado crítico, associando ensino formal e não-formal. A metodologia contempla a realização de cinco etapas estruturadas e interdependentes: observação da realidade e definição de um problema; pontos-chave; teorização; hipóteses de solução; e aplicação à realidade (BORDENAVE; PEREIRA, 1982 apud BERBEL, 2012).

Consoante Berbel (2012), na etapa de observação da realidade, os(as) alunos(as) problematizam a parcela da realidade, a qual deverá se relacionar com temas de estudo. Na busca por respostas para resolver o problema observado, nas etapas de pontos-chave e teorização, os(as) estudantes participam através do aprender-fazendo, estudando pontos teóricos e práticos para solução do problema da realidade concreta observada. Neste processo, cabe ao(à) professor(a) exercer a função de mediador(a), com constante valorização das iniciativas apresentadas pelos(as) alunos(as) para solução do problema. Assim, são realizadas aprendizagens de diversas ordens, como as de construção de instrumentos de busca de informações, tratamento destas, análise de dados coletados e registro e sistematização de informações. Nessa direção, os(as) estudantes constroem conhecimentos e alcançam a etapa das hipóteses de solução, quando estabelecerão possíveis soluções para 0 problema e escolhem àquelas que serão colocadas em prática na parcela da realidade da qual o problema foi extraído. Com essa perspectiva, a proposta desenvolvida através de cada etapa proporciona sentido para uma ação prática desenvolvida na realidade.

Isto posto, o objetivo deste trabalho foi analisar a relação socioambiental entre alunos(as) do $6^{\circ}$ ano, de uma escola municipal da Grande Aracaju, e o Parque Natural Municipal do Poxim (PNMP), por meio da metodologia da problematização. 


\section{Procedimentos metodológicos}

A pesquisa foi realizada em dois espaços: formal e não-formal de ensino e aprendizagem. Quanto ao espaço formal, o estudo foi realizado com 30 alunos(as) do $6^{\text {a }}$ ano do ensino fundamental de uma Escola Municipal da Grande Aracaju. A escola foi escolhida em virtude da proximidade com o Parque Natural Municipal do Poxim (PNMP), com cerca de $1 \mathrm{Km}$ de distanciamento. Esta Unidade de Conservação (UC) abrange uma área aproximada de $1.744 \mathrm{Km}^{2}$, essencialmente composta por remanescentes do Bioma Mata Atlântica, predominando ecossistema de manguezal, no entorno dos bairros São Conrado, Farolândia e Jabotiana, localizados em Aracaju (DECRETO no 5370, 2016).

A pesquisa atendeu às questões éticas exigidas pelo Comitê de Ética da Universidade Federal de Sergipe, aprovada a partir do parecer final de número: 3.594.315. Para assegurar a confidencialidade da identidade dos(as) estudantes foi feita codificação com a letra $A$ e um número que representa cada sujeito da pesquisa (A1, A2, A3...An).

Esta pesquisa segue uma abordagem quali-quantitativa e utilizou-se de técnicas da investigação ação-participativa (MARCONI; LAKATOS, 2010), com o desenvolvimento dos cinco passos da metodologia da problematização conforme Bordenave e Pereira (2000): observação da realidade, seleção dos pontos-chave, teorização, hipóteses de solução e aplicação à realidade (Figura 1).

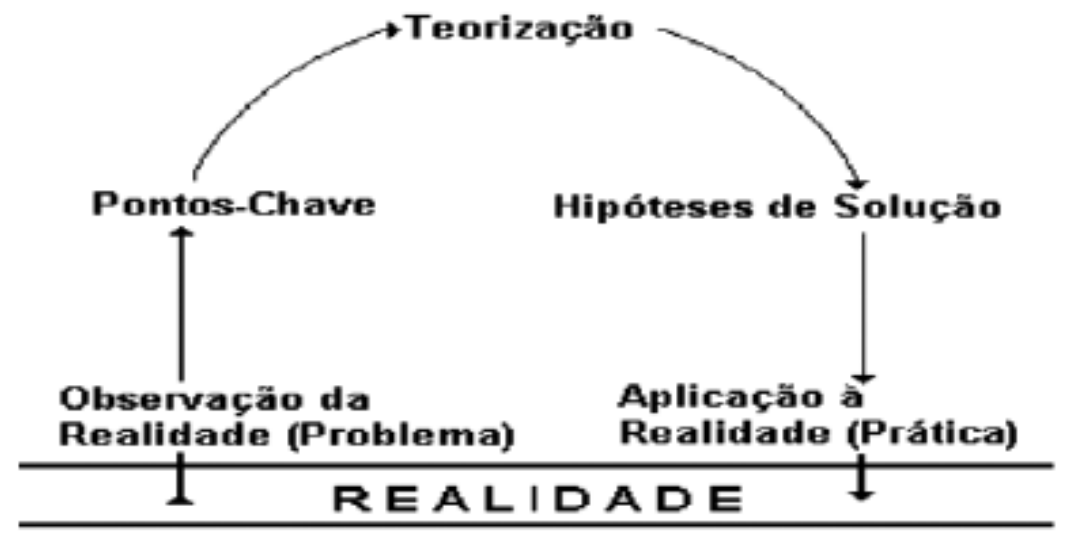

Figura 1: Arco de Charles Maguerez. Fonte. Bordenave e Pereira (2000).

Etapa 1 - Observação da realidade: para a visita de campo foram escolhidos três pontos de visitação, sendo dois pontos localizados no entorno do Parque (P1 e P2) e um ponto em área pertencente ao Parque Natural (P3). Nos pontos definidos, os(as) estudantes, poderiam observar o Rio Poxim e seu afluente, o Rio Pitanga, locais que têm sofrido influência da antropização. Os(as) alunos(as) deveriam fazer registros escritos seguindo um roteiro de campo, no qual havia questões sobre descrição do local de visita, sensações durante o tempo de permanência nos locais e existência ou não de alterações 
do ambiente provocadas pelos seres humanos. As perguntas tinham o objetivo de identificar a relação individual de cada aluno(a) com o PNMP e seu entorno.

Etapa 2 - Seleção dos Pontos-chave: após o trabalho de campo, foi realizada uma roda de conversa em sala de aula, com todos os(as) alunos(as) da turma, para compartilhar as experiências vividas. Posteriormente, uma adaptação da técnica de Carta apresentada por Verona (2009) foi utilizada para coletar dados quali-quantitativos. A atividade consistiu em entregar uma Carta com perguntas direcionadas para identificação dos problemas socioambientais nos pontos de visitação: 1) Quais os problemas detectados por vocês nos locais que visitamos?; 2) Qual desses problemas vocês acham mais graves para o meio ambiente? Qual deles podemos ajudar a solucionar? 3) Quem é o responsável por esse problema? 4) Por que será que existe esse problema na sua região? Qual a causa desse problema?

Nessa etapa, foram criados grupos de trabalho, cada um com seis alunos(as), inclusive com os(as) alunos(as) que não participaram da etapa da observação da realidade, através de sorteio para a etapa seguinte, a da teorização. Estes grupos passaram a ser fixos até a finalização da pesquisa.

Etapa 3 - Teorização: cada grupo de estudantes ficou responsável por pesquisar temas envolvidos com esta pesquisa como, por exemplo: Parque Natural, Parque Natural Municipal do Poxim, Rio Poxim e Mata Atlântica. Todos(as) foram orientados a buscar informações sobre resíduos sólidos e as consequências do descarte incorreto. As informações deveriam ser consultadas em livros, revistas especializadas sobre o assunto, pesquisas na Internet, jornais etc.

Etapa 4 - Hipóteses de solução: para melhor orientar nessa etapa foram realizadas as seguintes perguntas coletivamente em sala de aula: $O$ que precisa acontecer para que o problema seja solucionado? $O$ que precisa ser providenciado? $O$ que pode realmente ser feito? Os(as) alunos(as) responderam às perguntas por meio de discussão oral e a partir daí foram orientados a elaborar suas hipóteses em grupo. As respostas dos grupos foram sistematizadas na lousa para posterior análise das hipóteses passíveis de execução. Como parte da etapa foi oferecida aos(as) estudantes uma oficina de "construção de folhetos" para familiarizá-los com a produção de materiais relacionados ao problema.

Etapa 5 - Aplicação à Realidade: esse foi o momento em que foram executadas as soluções sugeridas pelos estudantes para 0 problema socioambiental selecionado na etapa de seleção dos pontos-chave.

Quanto à análise dos dados, as falas dos(as) alunos(as) durante todas as etapas da problematização e as respostas às questões do roteiro de campo e da Carta para seleção dos pontos-chave foram agrupadas de acordo com critérios quali-quantitativos. Estes materiais serviram de base para técnica de análise do discurso. Barros (2015, p. 76) afirma que: 
A Análise do Discurso não se preocupará com o sentido do texto ou com o discurso, mas com os modos como o texto e o discurso se relacionam na produção de sentidos ao longo do seu percurso histórico, como uma palavra que adquire sentidos em determinada conjuntura.

A pesquisa se desenvolveu através da exploração, descrição e explicação dos elementos que compuseram os discursos. Os procedimentos adotados para a análise do discurso dos sujeitos da pesquisa foram: análise exploratória inicial das falas ou respostas dos sujeitos da pesquisa, cujo objetivo era determinar a ocorrência ou não das hipóteses elencadas para as perguntas interligadas com o objetivo do estudo. Em seguida, foi realizada a escolha das fontes bibliográficas contendo os conceitos chave identificados nos discursos. Nessa etapa, buscou-se inferir sobre ações desenvolvidas em escolas sob a vertente da Educação Ambiental crítica e sua relação com os Parques naturais como objetos de sensibilização ambiental. A busca pelos conceitos chaves dentro dos textos e fontes escolhidas permitiu a análise crítica dos discursos e as formas como esse discurso estendeu-se para as práticas durante a aplicação da metodologia da problematização.

\section{Resultados e discussão}

\section{Observação da realidade}

Ao chegarmos ao primeiro ponto de visita foi entregue aos(as) alunos(as) o roteiro de campo para melhor orientá-los na observação e na análise do espaço não-formal de ensino, assim como facilitar a busca de informações pela pesquisadora sobre a interação dos(as) alunos(as) com o PNMP e suas áreas adjacentes. Em relação aos P1 e P2 houve respostas variáveis descrevendo os locais como arejado ou abafado, confortável ou desconfortável, silencioso ou barulhento e geralmente não agradável. Apesar de não agradável, os(as) alunos(as), especialmente do gênero masculino, afirmaram visitar frequentemente o P1 para tomar banho no rio, pescar ou brincar. Os mesmos estudantes afirmaram, durante a visita ao local, nunca ter ido visitar esses locais em ações de Educação Ambiental promovidas pela escola, apesar da proximidade e deste ser adequado para emprego de metodologias ativas com foco em Educação Ambiental.

Pode-se inferir, a partir do discurso dos(as) alunos(as), que as escolas, embora precisem trabalhar com Educação Ambiental de forma transversal, frequentemente não consideram as UCs e suas proximidades como áreas que promovam oportunidade de ações de investigação ambiental. A fim de mudar essa realidade, o ICMBio (Instituto Chico Mendes de Conservação da

Biodiversidade) publicou um guia orientador contendo estratégias metodológicas participativas para que gestores escolares e professores que atuem próximos da área de influência das UCs se tornem parceiros 
estratégicos na promoção da conservação desta sociobiodiversidade (BRASIL, 2016). Os parques naturais, especialmente aqueles localizados no ambiente urbano, são espaços adequados para a construção de uma consciência ecológica, por meio do contato direto com os elementos da natureza colaborando com a conservação dos recursos naturais (FERNANDES; HIGUCHI, 2017). Os professores têm um papel fundamental, fazendo com que os(as) estudantes adquiram compreensão da importância de se construir uma sociedade mais igualitária e ambientalmente sustentável (JACOBI, 2003).

Quanto ao ponto três (P3) os(as) alunos(as), em unanimidade, relataram - local como arejado, confortável, silencioso e agradável. Essa sensação agradável provavelmente deve-se à estrutura diferenciada do local, pois estão presentes pistas pavimentadas, mesas e cadeiras de cimento, brinquedos, além de ser um ambiente mais arborizado, o que atraía animais, como pássaros, insetos, peixes etc, o que não foi possível observar nos demais locais de visita. Essa infraestrutura possibilitou a execução de diferentes atividades de lazer e de contemplação da natureza, por esse motivo foi onde passamos o maior período. Nesse local, diferentes motivações partiram dos(as) alunos(as) por meio das falas ou atitudes: parte dos(as) alunos(as) demonstrou ter interesse na estrutura montada para lazer, enquanto outros manifestaram a importância da contemplação da natureza proporcionada por um ambiente limpo, seguro e bonito visualmente.

Segundo Fernandes e Higuchi (2007) vários motivos podem levar o visitante a se deslocar até um parque natural urbano, como por exemplo, contato com a natureza, bem-estar, saúde e lazer. Os autores observaram que a infraestrutura do Parque do Mindu em Manaus (AM) proporciona um ambiente seguro, tranquilo e agradável, sensações também evidenciadas neste trabalho, no ponto de visita três (P3). Salienta-se que esse local na cidade de Aracaju, conhecido como Praça do Inácio Barbosa e que pertence ao PNMP, é bem frequentado, especialmente por moradores desta proximidade e também é utilizado por educadores ambientais da Secretaria Municipal de Meio ambiente (SEMA/Aracaju-SE) em ações em escolas públicas para promover divulgação do Parque natural.

Os(as) alunos(as) foram perguntados se gostariam de voltar aos locais visitados, apesar de ter sentido desconforto em alguns locais. Todos disseram que voltariam ao ponto três (P3), a Praça do Inácio Barbosa, por ser um local agradável e que proporciona atividades de lazer. Da mesma foram disseram que voltariam ao ponto um (P1), por causa do contato com a natureza. No entanto, estes afirmaram que o espaço precisa de melhorias, pois é poluído e não tem infraestrutura adequada para diversão.

O uso e a função dos parques naturais e dos parques urbanos como ambientes de sensibilização da comunidade frente aos problemas socioambientais vêm sendo discutido em vários trabalhos publicados desde a última década. Ao avaliar o uso dos parques verdes localizados na área urbana de Sorocaba (SP), independentemente deste ser categorizado como UC ou não, Kachinski (2018) observou que os parques mais bem avaliados nos Revbea, São Paulo, v.16, № 1: 410-429, 2021. 
quesitos infraestrutura, manutenção e segurança estão nas regiões onde a população apresenta maior renda fazendo com que sejam mais frequentemente visitados, fato também observado neste trabalho, já que a área pertencente ao PNMP (P3) é a que possui melhor infraestrutura e está localizado em bairro de classe média à alta de Aracaju. $O$ contrário dessa situação foi observado na primeira área visitada (P1), pois apesar de possuir vegetação natural e também estar localizado na proximidade do rio Poxim, salienta-se que a infraestrutura improvisada para recreação nesse local foi montada pela própria comunidade para uso recreativo, fato que foi retratado pelos(as) alunos(as) durante à visita de campo. Diante dessa percepção, ações promovidas por educadores ambientais na comunidade daquela região poderiam estimular a luta por melhor infraestrutura, assim como a implantação de um parque verde urbano ou a inclusão dessa área nos limites do PNMP devido à sua proximidade com esta UC e diversas escolas. Soares et al. (2002) afirmam que uma prática de Educação Ambiental bem aplicada pode levar informações às diversas camadas da população e, consequentemente, as pessoas podem compreender a sua realidade, estimulando-as a tomar atitudes diante da sociedade e dos governos para resolver os problemas socioambientais locais, tornando-os cidadãos reflexivos, participativos e transformadores do seu ambiente.

Todavia, apesar do P3 ter infraestrutura para lazer, talvez por pertencer ao PNMP, este ainda carece de intervenções por parte do poder público para que possa ser utilizado pela comunidade como ambiente de sensibilização ambiental. Salienta-se que o espaço possui placa indicativa de espaço pertencente ao PNMP, no entanto não existem indicações da fauna e flora do local, não existe trilha interpretativa, nem estrutura para conforto dos usuários como banheiros ou bebedouros, assim como não há um Centro de apoio com monitores especializados em Educação Ambiental, conforme é observado em parques naturais localizados em áreas urbanas do estado de São Paulo, como - Parque Estadual Campina do Encantado e o Parque Natural Municipal Fazenda do Carmo (SÃO PAULO, 2014, 2020).

Nesse sentido, o IBAMA salienta que para um efetivo uso público da UC aliando Educação Ambiental $\times$ lazer coletivo deve existir na zona de uso intensivo do parque natural um Centro de visitantes. O ambiente é mantido o mais próximo possível do natural, podendo conter infraestruturas de suporte ao uso público com equipamentos compatíveis à implementação do programa de uso público da Unidade. Raimundo et al. (2011) indicam algumas parcerias importantes como, por exemplo, com as escolas públicas, no qual atividades de Educação Ambiental em espaços não formais devem ser priorizadas. O parque pode ser usado como um grande tema gerador trabalhado pelo currículo escolar. Assim sendo, parques naturais são laboratórios vivos à disposição dos professores, onde os(as) alunos(as), além de contemplar a natureza e se divertirem podem ser sensibilizados acerca das questões ambientais locais. Por isso, a próxima etapa da pesquisa foi fundamental para continuidade do projeto.

revista brasileira educação ambiental 


\section{Seleção dos pontos-chave e teorização}

Em relação às duas primeiras perguntas da Carta para seleção dos pontos-chave, os(as) alunos(as) destacaram alguns problemas socioambientais, especialmente observados nos P1 e P2: "lixo" (47\%), desmatamento (26\%) e poluição (26\%). Quanto ao tipo de resíduos sólidos descartados nos locais, verificou-se a presença de garrafas de plástico, latas de refrigerante, papel, restos de construções e pedaços de madeira. Em relação a P3, os(as) alunos(as), de maneira geral, destacaram presença de resíduos sólidos, porém em menor proporção e, também destacaram ponte de madeira (píer) precisando de reparos. Devido à maior prevalência do problema socioambiental citado pelos(as) alunos(as) ter sido os resíduos sólidos (47\%), este foi selecionado como ponto-chave para elaboração das possíveis hipóteses de solução.

Silva e Campos (2016) também evidenciaram problemas socioambientais no Parque municipal Carmo Bernardes (Goiânia/GO) e seu entorno, semelhantes ao evidenciado neste trabalho como, por exemplo, resíduos sólidos de toda natureza espalhados pelo parque, falta de manutenção em infraestrutura, assoreamento do córrego São José, ocupação irregular das áreas do entorno do parque, dentre outros. Os autores recomendam que parcerias com instituições de ensino com o objetivo de elaborar projetos de divulgação das potencialidades do parque e da sua importância poderiam ser alternativas eficientes para minimizar os problemas socioambientais locais identificados.

Ao avaliar problemas socioambientais urbanos do município de Criciúma (SC), Munari et al. (2018) buscaram uma compreensão do meio ambiente associado aos aspectos socioculturais, econômicos e políticos, o que possibilitou o rompimento da noção de meio ambiente associada apenas às áreas verdes, integrando-o ao ambiente construído, o que possibilita o enfrentamento de problemas da realidade local. Com a aplicação da metodologia da problematização, os estudantes de diversos cursos de graduação apresentaram soluções para diversos problemas socioambientais, inclusive o descarte inadequado de resíduos sólidos, utilizando áreas do conhecimento multidisciplinares, como, por exemplo, engenharias, ciências biológicas, direito, psicologia e educação física.

A questão do lixo vem sendo apontada pelos ambientalistas como um dos mais graves problemas ambientais urbanos da atualidade, por isso tem se tornado alvo de programas de Educação Ambiental nas escolas com vistas a seu enfrentamento responsável. Além disso, esse tema tem um viés prático muito grande, sendo frequentemente selecionado como um tema gerador quando da execução de metodologias participativas no âmbito da EA (LAYRARGUES, 2002). É fundamental desenvolver atividades de Educação Ambiental no sentido de motivar maior participação do cidadão no sistema de limpeza municipal, mostrando-Ihe as consequências ambientais, econômicas e sociais de atos simples e diários como o acondicionamento dos resíduos de forma correta, em locais e horários adequados, o varrer e conservar limpas as Revbea, São Paulo, v.16, № 1: 410-429, 2021. 
calçadas, dentre outras. A política dos 5 Rs (Refletir, Recusar, Reduzir, Reutilizar e Reciclar) é um importante instrumento pedagógico, que estimula o desenvolvimento da consciência ambiental em relação aos hábitos do consumo. É necessário realçar a importância da redução dos resíduos produzidos antes mesmo de se falar da reutilização e da reciclagem, pois o consumo consciente poupa os recursos naturais necessários à produção de novos produtos (QUERINO et al., 2018).

Durante a etapa da seleção dos pontos-chave desenvolvida na sala de aula referente ao problema socioambiental dos resíduos sólidos foram expostas informações sobre a política dos 5 Rs e a coleta seletiva dos resíduos sólidos inorgânicos. De forma geral, os(as) alunos(as) relataram desconhecer a política dos $5 \mathrm{Rs}$, assim como os procedimentos relacionados com a coleta seletiva dos resíduos sólidos, inclusive foi notório o desconhecimento em relação ao programa de recolhimento dos resíduos inorgânicos desenvolvido pela Prefeitura Municipal de Aracaju, apesar do bairro ter sido o primeiro a ser contemplado no Projeto "Cidadão consciente, cidade limpa", que teve como objetivo orientar e conscientizar sobre os benefícios da coleta seletiva. A falta de conhecimento dos(as) alunos(as) em relação ao projeto e ao procedimento de coleta seletiva é justificada, pois o projeto foi lançado no ano de 2012, quando os(as) alunos(as) tinham em média 4 anos de idade, no entanto esses relatos reforçam a ideia de que ações de Educação Ambiental devem ser contínuas e permanentes, especialmente no ambiente escolar.

No terceiro questionamento, os(as) alunos(as) disseram que os responsáveis pelo problema eram os próprios seres humanos, as pessoas que moram no Bairro. Alguns se incluíram como causadores deste problema escrevendo "nós". Destacam-se algumas respostas: A1: "Porque as pessoas não sabem que é um Parque Natural e também por falta de consciência"; A5: "Porque eles não têm respeito pela natureza"; A7: "Os seres humanos não colaboram com o meio ambiente" e A12: "Falta de conhecimento".

Ribeiro e Affonso (2012) ao avaliarem a percepção ambiental de alunos(as) residentes na proximidade da Bacia Hidrográfica do Córrego São Pedro (Juiz de Fora/MG) também identificaram que os(as) alunos(as) percebem o descarte incorreto de resíduos sólidos como problema socioambiental importante. Parte dos(as) alunos(as) entrevistados (60\%) também identificaram forte interferência dos moradores nas condições naturais deste córrego. Vale destacar que quando os(as) alunos(as) percebem-se como "causadores" dos impactos ambientais revela-se a criticidade dos(as) alunos(as) frente aos problemas ambientais. Carvalho (2012) orienta que a tomada de consciência ecológica deve ser iniciada nas séries iniciais do ensino infantil para que o indivíduo torne-se um sujeito ecológico num processo natural. Segundo a autora um sujeito ecológico é aquele que apresenta postura crítica frente à questões como exploração dos recursos do meio ambiente sem real necessidade para sua sobrevivência e desigualdade socioambiental. Segundo Torres et al. (2014) a EA tem um papel fundamental na construção de conhecimento quando está fundamentada em temas geradores (e 
problematizadores) que coloquem o(a) estudante como ponto central das discussões em sala de aula, valorizando o seu conhecimento prévio e, se preciso, promovendo a mudança conceitual.

$\mathrm{Na}$ etapa de teorização, quase a totalidade dos(as) alunos(as) (com exceção de um) não demonstrou interesse em realizar a pesquisa teórica, por isso esta etapa foi remarcada por duas vezes. Provavelmente este fato aconteceu porque a maioria dos(as) alunos(as) já tinha atingido a média mínima para aprovação na disciplina de Ciências, já que esta pesquisa foi realizada no final do ano letivo. Além disso, a maioria da turma alegou não ter acesso à internet em casa e nem na escola, fato que também é relatado em trabalhos da área. Para que esse problema fosse solucionado a pesquisadora levou materiais como reportagens de jornal, livros didáticos de ciências e cartilhas educativas para a sala de aula.

Ao considerar a importância de avaliar o uso da metodologia ativa Problematização em uma escola pública, é relevante também considerar os entraves da pesquisa. Durante os resultados obtidos em diversas etapas da metodologia, percebeu-se que os(as) alunos(as) apresentaram dificuldade em dar sequência às etapas necessárias para finalização deste projeto. Como possíveis argumentos para tais dificuldades apresentam-se fatores como: a falta de costume de atuar de forma ativa, o despreparo cognitivo/emocional para executar algumas atividades, a aprovação na disciplina de Ciências antes da execução da pesquisa o que provavelmente interferiu no fator motivação, dentre outros.

Segundo Berbel (2014) muitos alunos(as) estão habituados a trabalhar no sistema tradicional com uma forma pedagógica mais conservadora. Estão acostumados a receber informações, assim reagem negativamente quando são solicitados a ter uma nova forma de atuar. De acordo com a Base Nacional Comum Curricular (BNCC) (BRASIL, 2017) os(as) alunos(as) devem ser estimulados a realizar atividades investigativas definindo problemas, compartilhando experiências e por fim propondo intervenções. Esse conjunto de etapas pode ser alcançado através das metodologias ativas, como a problematização, desde que bem orientadas pelo professor-mediador.

\section{Hipóteses de solução e aplicação à realidade}

Os(As) alunos(as) demonstraram dificuldade em elaborar uma hipótese de solução que envolvesse o problema socioambiental detectado na etapa da observação da realidade. Em meio à dificuldade, foi solicitado que refletissem principalmente acerca dos problemas dos resíduos sólidos e na estrutura do local do $1^{\circ}$ ponto de visitação, uma vez que a localidade está: a) situada próximo da Escola Municipal de Ensino Fundamental (E.M.E.F.) e do Parque Natural Municipal do Poxim; b) os(as) alunos(os) e a comunidade local poderiam visitá-la para lazer ou atividades promovidas pela escola, diante da facilidade de acesso e c) os(as) alunos(as) manifestaram incômodo com relação à infraestrutura improvisada do local e o descuido com o descarte de resíduos sólidos pela população local.

Revbea, São Paulo, v.16, № 1: 410-429, 2021. 
Consoante Berbel (2014), a elaboração de um problema de estudo é a etapa mais difícil da metodologia da problematização, pois somos acostumados a responder problemas trazidos pelos professores. No entanto, salienta-se que essa questão se torna mais fácil quando o problema é real e nos sentimos incomodados com ele, formando cidadãos críticos e reflexivos conforme preconiza a EA crítica. Não se pode especificar exatamente uma idade cronológica para trabalhar com metodologias ativas, mas segundo a autora as séries escolares, a partir $5^{\circ}$ ou $6^{\circ}$ ano, já são suscetíveis de apresentar bons resultados, quando estimulados.

Nessa etapa todos os(as) alunos(as) participaram coletivamente e sugeriram perguntas que poderiam conduzir às hipóteses de solução em um processo de construção do conhecimento: A6: "Por que as pessoas jogam lixo no chão?" e A7: "As pessoas não sabem que o lixo acaba indo parar no rio Poxim?". Dando continuidade, foi perguntado aos educandos: de que modo a área do P1 poderia ficar estruturada como a área do P3. Os(as) alunos(as) responderam: A5: "Professora poderíamos colocar mais plantas lá"; A7: "Poderíamos também colocar bancos para que a gente pudesse olhar a natureza. Poderíamos falar com alguém importante que nós queríamos que aqui virasse o Parque Natural para a gente poder brincar e passar uma tarde lá. Eu passaria a tarde toda lá".

Paulo Freire propõe uma educação cuja prática educativa possua a essência formadora da natureza humana. Ao educador, cabe o papel de provocar e construir (FREIRE, 2015). Essa perspectiva freireana relaciona-se com a abordagem pautada nas metodologias ativas, nas quais o(a) estudante assume o papel de sujeito protagonista, reflexivo e participativo. Ademais, podemos sinalizar que a fala do(a) estudante A7 revela um dos pontos fundamentais da EA crítica: a capacidade de enfrentar os problemas a partir da intervenção. A corrente crítica prevê ações na sociedade enquanto perspectivas de emancipação e transformação das situações concretas (TORRES et al., 2014). Segundo Santos et al. (2019) a metodologia da problematização, pautada nos cinco passos do arco de Maguerez, apresentase como uma proposta puramente voltada para as interações entre aluno(a)/professor e aluno(a)/comunidade, resultando em identificação por parte dos alunos(as) de um sentimento concreto de pertencimento ao local escolhido para 0 enfrentamento de problemas socioambientais com possibilidade de uma contrapartida social, com frutos a curto prazo.

Diante de toda essa discussão e sistematização no quadro das sugestões dadas pelos educandos foi escrita na lousa a pergunta-problema para que eles pensassem em outras soluções: "O que poderíamos fazer para que os moradores da região soubessem da existência do Parque Natural Municipal do Poxim e não jogassem mais resíduos sólidos nas proximidades do rio Poxim?".

Cerca de cinco alunos(as) revelaram outras ideias para minimizar o problema dos resíduos sólidos: colocar lixeiras de coleta seletiva e placas de 
advertência - Não jogue lixo! Preserve o Rio Poxim! Enquanto várias outras sugestões foram dadas com o intuito de organizar melhor o P1: conversar com os moradores sobre o rio Poxim, o Parque Natural e o descarte incorreto de resíduos sólidos, colocar bancos para contemplar a natureza, plantar mudas de plantas frutíferas para tornar o ambiente mais agradável, escrever uma carta para gestores públicos a fim de solicitar mudanças estruturais no local e confeccionar um folheto com informações sobre o Parque Natural Municipal do Poxim para divulgação e sensibilização das pessoas da comunidade.

Das sugestões dadas(as) pelos alunos(as) selecionamos duas para a etapa da aplicação à realidade considerando o tempo de execução que teríamos disponível para fazê-lo (apenas uma semana): confecção de folheto de divulgação do Parque Natural Municipal do Poxim, contendo informações sobre o descarte correto dos resíduos sólidos e a formulação da Carta de intenções para ser entregue aos gestores políticos, com o propósito de incluir a área selecionada pelos(as) alunos(as), o ponto um (P1), na área do Parque Natural Municipal do Poxim e organizá-lo estruturalmente como na área do Parque do Inácio Barbosa (P3).

Antes dos(as) alunos(as) iniciarem a tarefa foi ministrada oficina de construção de folheto. Fornazari e Obara (2017) afirmam que o professor deve selecionar metodologias de ensino que estejam relacionadas com os seus objetivos pedagógicos; assim se a intenção é formar um cidadão crítico, reflexivo e participativo, as oficinas pedagógicas que estão pautadas na açãoreflexão e no aprender fazendo podem ser importantes aliadas. Na execução do folheto observou-se que os grupos que visitaram o Parque Natural envolveram-se com mais empenho e atenção às etapas desenvolvidas. De forma geral, o folheto ficou organizado, tanto estruturalmente quanto nas informações a serem divulgadas (Figura 2). No folheto percebeu-se que os(as) alunos(as) quiseram destacar a função do PNMP quanto à preservação das espécies de animais e plantas. Sobre o rio Poxim levantaram um questionamento "Você concorda que o rio Poxim precisa ser preservado?". Percebe-se nesse questionamento que os(as) alunos(as) gostariam que as pessoas refletissem sobre a importância do rio para a comunidade aracajuana, provavelmente devido a quantidade de resíduos sólidos observados na sua margem durante a etapa da observação da realidade. O grupo responsável pelo tema Mata Atlântica, após discussão, escreveu sobre o desmatamento e finalizou chamando a atenção do(a) leitor(a) com a frase: Preserve a Mata Atlântica!. Na última parte do folheto os(as) alunos(as) responsáveis pelo tema Resíduos sólidos destacaram as vantagens da coleta seletiva como uma alternativa para a redução do descarte incorreto dos resíduos sólidos. Nessa parte os(as) alunos(as) divulgaram o dia da coleta seletiva no bairro e inseriram figura contendo informações sobre o tipo de material apropriado para reciclagem e a cor respectiva das lixeiras para papel, plástico, vidro e metais. 


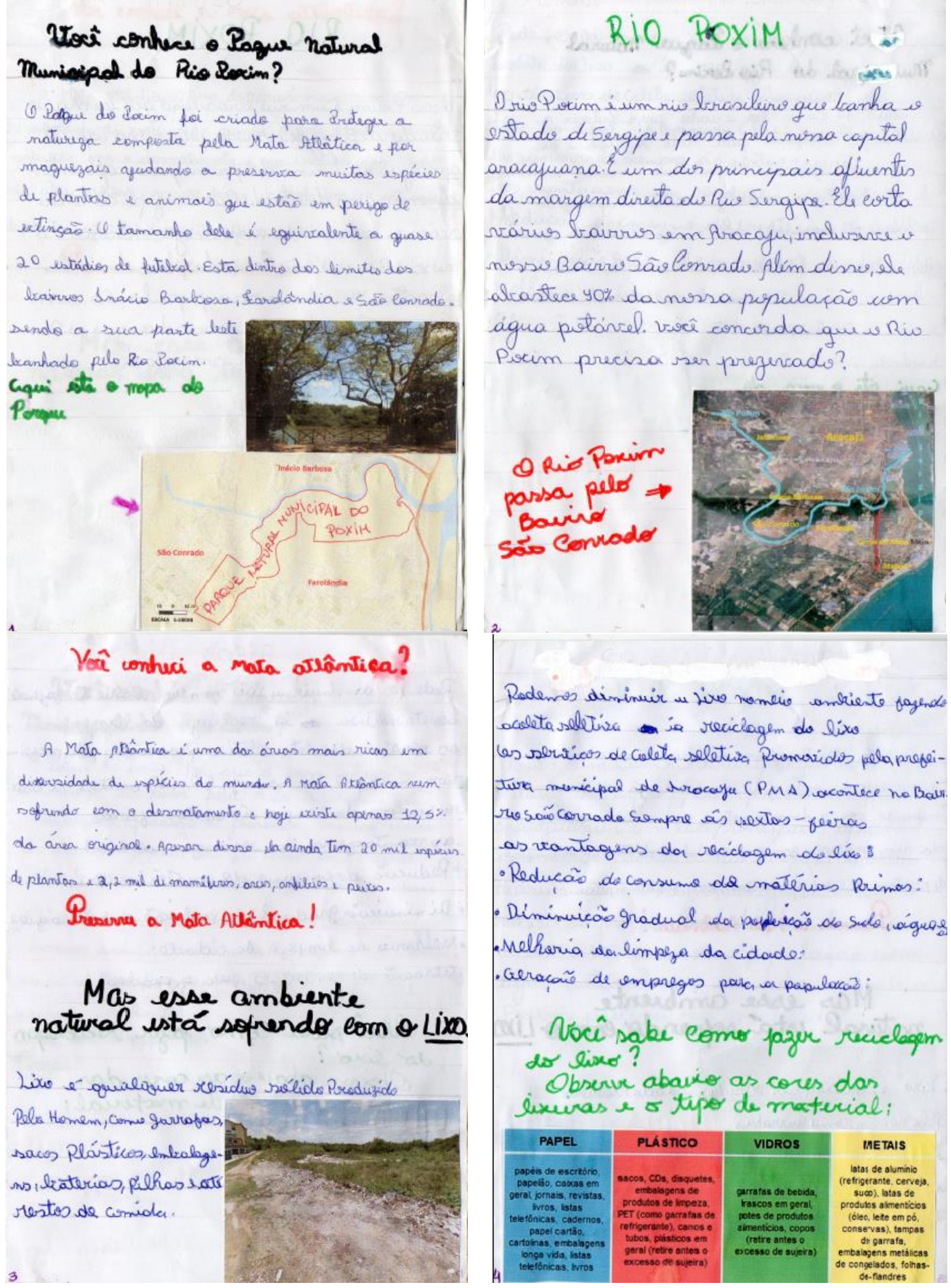

Figura 2: Folheto produzido pelos alunos(as) na etapa da elaboração das hipóteses de solução para ser entregue nas ruas próximas à E.M.E.F. Fonte: autora da pesquisa, 2019.

No dia da aplicação à realidade foram distribuídas cópias do folheto definitivo elaborado pelos próprios alunos(as) para que pudessem dar sua opinião. De maneira geral, os(as) alunos(as) gostaram do resultado. Após leitura do folheto por todos destaca-se a fala de um aluno: A5: Professora, ficou muito legal. Posso levar pra casa! Apesar disso, apenas quatro alunos(as) se dispuseram voluntariamente a entregar as cópias do folheto na proximidade da

Revbea, São Paulo, v.16, № 1: 410-429, 2021.

revista brasileira educação ambiental 
E.M.E.F. Quanto à execução da Carta de intenções, apenas seis alunos(as) quiseram voluntariamente escrever o bilhete a ser anexado ao texto da autora da pesquisa, a ser entregue à Secretaria Municipal de Meio Ambiente (Aracaju/SE), órgão responsável pela gestão do Parque Natural Municipal do Poxim. Os(as) alunos(as) destacaram nos seus bilhetes o que deveria ser colocado na praça para que fosse um ambiente de lazer e contemplação da natureza (Figura 3).

\section{CARTA DE INTENÇÕES}

Prezados gestores públicos,

Venho por meio desta carta encaminhar as intenções dos(as) alunos(as) do $6^{\circ}$ ano B da E.M.E.F. da Grande Aracaju, a fim de obter melhorias na área localizada próximo das casas dos(as) alunos(as), da escola municipal e do Parque Natural Municipal do Poxim e com o intuito de que, futuramente, este local possa fazer parte da área protegida do referido Parque Natural. Após visitas realizadas pelos(as) alunos(as), conduzidas por mim e pela coordenadora pedagógica da escola, nas proximidades da Av. Francisco José de Fonseca (ao lado da ponte nova do Rio Poxim), constatamos que essa área poderia se transformar em um local de lazer e contemplação da natureza pelos frequentadores da localidade. Atualmente, o local tem servido para jogar entulhos de construção e lixo e/ou resíduos sólidos) (de diversos tipos) e a natureza em volta dessa área, que faz parte da Mata Atlântica, encontra-se degradada. Para que as ideias dos(as) alunos(as) não caiam no esquecimento e fiquem apenas no papel, sem trazer nenhum benefício para os mesmos e a comunidade do entorno da escola, decidimos elaborar esta Carta aos gestores (trechos das cartas dos(as) alunos(as) em anexo). Como representante político desta cidade gostaríamos de contar com a sua atenção para que no futuro esse espaço seja lembrado como uma conquista da comunidade escolar e fruto da vontade política de oferecer uma melhor qualidade de vida para sua população.

Trechos das Cartas dos(as) alunos(as):

Prezado Senhor, meu nome é A1. Eu quero que nesse local coloquem mudas e placas avisando que é um parque natural. Eu agradeço. Obrigado.

Meu nome é A5. Sou da escola do bairro São Conrado. Eu quero que coloquem placas para não jogar lixo, coloquem lixeiras.

Meu nome é A18. Estudo na E.M.E.F. da Grande Aracaju eu quero que plantem mais mudas, coloquem mais bancos, lixeira adequadas e mais placas.

Meu nome é A6. Eu estudo na Escola do Bairro São Conrado. Eu quero que coloque mais lixeiras no parque natural do rio poxim e que não joguem mais lixo no rio Poxim.

Eu quero que estalem alguns brinquedos para as crianças brincar e coloquem mais plantas $e$ algumas lixeiras para o povo colocar o lixo. A20.

Meu nome é A7. Moro no São Conrado. Eu estou pedindo a você que está lendo esse bilhete. Estudo no Colégio do bairro São Conrado na série $6^{\circ} B$. Peço que você possa botar lixeiras, bancos, plantas, mudas frutíferas etc. Não quero muito só peço isso a vocês que ajudem o parque natural do rio poxim.

Com nossos melhores cumprimentos,

Grupo de Educadores e Educandos ambientais da EMEF 
De acordo com Santos et al. (2019, p. 36-37),

[...] diferentes conceitos e estratégias são abrangidos pela Metodologia da Problematização com o arco de Maguerez quando esta se concretiza, antes mesmo de ser finalizada, a exemplo de debates, estudo do meio, o olhar social, ações de cidadania, ética e saúde, onde também está implícita a discussão ambiental. Dessa forma, a problematização pode ser relacionada diretamente em uma perspectiva socioambiental, pois não dissocia em fragmentos o processo de ensinoaprendizagem.

\section{Conclusões}

Os(as) alunos(as) foram capazes de realizar todas as etapas do Arco de Maguerez. As ações revelaram o quanto a metodologia promoveu o protagonismo e a criticidade dos(as) alunos(as) sobre um Parque que deveria fazer parte do cotidiano da escola. O método do Arco permitiu que os(as) alunos(as) enxergassem o PNMP e seu entorno como um local dotado de problemas socioambientais e que exige tomada de providências por parte da gestão pública do município. Fato representado na carta supracitada e que mostra, enquanto produto final deste trabalho, a capacidade da EA Crítica, trabalhada mediante o uso de metodologias ativas, de transformar sujeitos que estão dentro da escola, para além dos seus muros.

Espera-se que os(as) alunos(as) atuem multiplicando os saberes, demonstrando mudança nos valores e atitudes frente ao meio ambiente, embora se saiba que para haver uma mudança mais efetiva de hábitos e de comportamentos, é necessário um processo de EA contínuo e permanente. Embora com adaptações e reformulação de estratégias a metodologia mostrou como os(as) alunos(as) relacionavam-se com o PNMP e ao mesmo tempo, ao observar a realidade local, os mesmos foram capazes de sugerir hipóteses de solução para a melhoria do seu local de moradia. Observou-se, criatividade e criticidade, especialmente por parte de alguns estudantes específicos quando se refletiu sobre o principal problema socioambiental da comunidade local.

Sugere-se a continuidade da investigação da percepção dos(as) alunos(as) e da comunidade escolar em relação ao PNMP, pois a compreensão da importância das Unidades de Conservação para as pessoas que moram no seu entorno ajudará no entendimento de como essa população intervém na área e, ao mesmo tempo, possibilitará a construção de tomada de decisões, que assegurem os objetivos básicos dessas áreas protegidas para uma qualidade de vida atual e futura das comunidades envolvidas. 


\section{Referências}

ARACAJU. Decreto Municipal n. 5.370, de 03 de agosto de 2016. Dispõe sobre a criação do Parque Natural Municipal do Poxim, no âmbito do Município de Aracaju, e dá providências correlatas. Aracaju, SE, 2016. Disponível em: $<$ https://www.legisweb.com.br/legislacao/?id=327348>. Acesso em: 27 mai. 2018.

BARROS, T.H.B. (2015). Por uma metodologia do discurso: noções e métodos para uma análise discursiva. In: BARROS, T.H.B. (Org.). Uma trajetória da Arquivística a partir da Análise do Discurso: inflexões histórico-conceituais [online]. São Paulo: Editora UNESP, p. 73-95, 2015.

BERBEL, N. A. N. A Metodologia da Problematização em três versões no contexto da didática e da formação de professores. Rev. Diálogo Educacional, v. 12, n. 35, p. 103-120, 2012.

BERBEL, N.A.N. Metodologia da problematização: respostas de lições extraídas da prática. Semina: Ciências Sociais e Humanas, v. 35, p. 61-76, 2014.

BORDENAVE J. D.; PEREIRA, A. M. O que é ensinar. In: BORDENAVE, J.D.; PEREIRA, A.M. (ORG.). Estratégias de ensino-aprendizagem. Petrópolis-RJ: Vozes, p. 39-57, 2000.

BRASIL. Ministério do Meio Ambiente. Secretaria de Biodiversidade e Florestas. SNUC - Sistema Nacional de Unidades de Conservação da Natureza. PNAP - Plano Estratégico Nacional de Áreas Protegidas. Brasília: Ministério do Meio Ambiente, 2011. Disponível em: $<$ https://www.mma.gov.br/legislacao/areasprotegidas.html?download=1206:sist ema-nacional-de-unidades-de-conserva\%C3\%A7\%C3\%A3o-snuc-e-pnap>.

Acesso em: 8 abr. 2018.

BRASIL. Ministério do Meio Ambiente. Instituto Chico Mendes de conservação da Biodiversidade. Educação Ambiental em unidades de conservação: ações voltadas para comunidades escolares no contexto da gestão pública da biodiversidade - guia informativo, orientador e inspirador. Brasília: Ministério do Meio Ambiente, 2016.2 Disponível em: $<$ https://www.icmbio.gov.br/portal/images/stories/comunicacao/publicacoes/publ icacoes-

diversas/DCOM ICMBio educacao ambiental em unidades de conservacao. pdf >. Acesso em: 11 dez. 2019.

BRASIL. Ministério da Educação. Secretaria executiva. Base Nacional Comum Curricular - educação é a base. Brasília: Ministério da Educação, março de 2017.2 Disponível em: $<$ http://basenacionalcomum.mec.gov.br/images/BNCC El EF 110518 versaofi nal site.pdf>. Acesso em: 7 mar. 2019.

CARVALHO, I.C.M. Educação Ambiental: a formação do sujeito ecológico. São Paulo-SP: Cortez, 2012. 
FERNANDES, K. M.; HIGUCHI, M. I. G. Parques verdes urbanos: espaços de sensibilização ambiental e bem-estar social. Revista Ibero-Americana de Ciências Ambientais, v. 8, p. 23-36, 2017.

FERREIRA, R. A. et al. Nascentes da sub-bacia hidrográfica do rio Poxim, estado de Sergipe: da degradação à restauração. Revista Árvore, v. 35, 265277, 2011.

FORNAZARI, V.B.R.; OBARA, A,T. O uso de oficinas pedagógicas como estratégia de ensino e aprendizagem: a Bacia hidrográfica como tema de estudo. Investigações em Ensino de Ciências, v. 22, p. 166-185, 2017.

FREIRE, P. Pedagogia da autonomia: saberes necessários à prática educativa. Rio de Janeiro-RJ: Paz e terra, 2015.

JACOBI, P. Educação Ambiental, cidadania e sustentabilidade. Cadernos de Pesquisa, v. 118, p. 189-205, 2003.

KACHINSKI, K.V.B. O uso público nos parques urbanos e parques naturais de Sorocaba/SP. 2018. 101f. Dissertação (Mestrado em Sustentabilidade na Gestão Ambiental) - Centro de Ciências e Tecnologias para Sustentabilidade, Universidade Federal de São Carlos. Disponível em: <https://repositorio.ufscar.br/handle/ufscar/10585>. Acesso em: 01 abr. 2020.

LAYRARGUES, P.P. (2002). O cinismo da reciclagem: o significado ideológico da reciclagem da lata de alumínio e suas implicações para a Educação Ambiental. Disponível em: $<$ https://www.researchgate.net/publication/237655129 O CINISMO DA RECI CLAGEM o significado ideologico da reciclagem da lata de aluminio e su as implicacoes para a educacao ambiental 1>. Acesso em: 8 abr. 2020.

MARANDINO, M. et al. A educação não-formal e a divulgação científica: o que pensa quem faz? In: ENCONTRO NACIONAL DE PESQUISA EM EDUCAÇÃO EM CIÊNCIAS (ENPEC), 4, 2003, Bauru. Anais do [...]. Bauru: Associação Brasileira de Pesquisa em Educação em Ciências (ABRAPEC), 2003. p. 1-13. Disponível em: <http://abrapecnet.org.br/enpec/iv-enpec/orais/ORAL009.pdf>. Acesso em: 8 mar. 2019.

MARCONI, M. A.; LAKATOS, E. M. Fundamentos da Metodologia Científica. São Paulo-SP: Atlas, 2010.

MORAN, J. Mudando a educação com metodologias ativas. In: SOUZA, C.A.; MORALES, O.E.T. (Orgs.) Convergência Midiáticas, Educação e Cidadania: aproximações jovens. Ponta Grossa: Foca Foto-PROEX/UEPG, 2015. Disponível em: <http://www2.eca.usp.br/moran/wpcontent/uploads/2013/12/mudando moran.pdf>. Acesso em: 28 jul. 2018.

MUNARI, A.B. et al. Educação Ambiental e metodologia da problematização aplicadas aos problemas urbanos de Criciúma (SC). Revista Brasileira de Educação Ambiental, v. 13, n. 1, p. 76-86, 2018. 
NEPOMUCENO, A.L.O. A perspectiva participativa para a inserção da Educação Ambiental crítica na formação continuada de educadores ambientais. In: NEPOMUCENO, A.L.O.; MODESTO, M.A.; SANTOS, T.F. Educação Ambiental e formação de educadores: convergências para a práxis pedagógica. Curitiba-PR: Appris, p. 139-201, 2018.

QUERINO, L.A.L. et al. Análise da percepção dos moradores de São Sebastião de Lagoa de Roça (PB) quanto a redução, reutilização e reciclagem de resíduos sólidos. Revista Brasileira de Educação Ambiental, v. 13, n. 2, p. 228-245, 2018.

RAIMUNDO, S. et al. Construindo um programa de uso público para Unidades de Conservação em áreas metropolitanas: a experiência dos Parques Naturais Municipais de Itapecerica da Serra e Embu das Artes - RMSP (SP). OLAM Ciência \& Tecnologia, v. 11, p. 196-221, 2011.

REMPEL, C. et al. Percepção Ambiental da Comunidade Escolar Municipal sobre a Floresta Nacional de Canela, RS. Revista Brasileira de Biociências, v. 6, p. 141-147, 2008.

RIBEIRO, C.R.; AFFONSO, E.P. Avaliação da percepção ambiental de alunos do ensino fundamental residentes na bacia hidrográfica do Córrego São Pedro - Juiz de Fora/MG. Boletim de geografia, v. 30, p. 73-85, 2012.

SANTOS, L. R.; SOUZA, C. S. Degradação da qualidade das águas do rio Poxim em função do intenso processo de urbanização. Anais do II Congresso Internacional Gestão da água e Monitoramento ambiental. Aracaju, SE, 2015. Disponível em: <http://www.resag.org.br/congressoresag2015/anais/img/pdfs/ID 64.pdf>. Acesso em: 4 abr. 2018.

SANTOS, L.R.O.; SOUZA, R.M.; COSTA, J.J. Transposição metodológica: a problematização com o Arco de Maguerez no diálogo com a educação básica. In: SANTOS, L.R.O. (Org.) Práticas de Ensino na Comunidade: conceitos, contextos e dialogicidade. Aracaju: Criação Editora, p. 15-38, 2019.

SÃO PAULO. Secretaria do Verde e Meio ambiente. Plano de Manejo: Parque Natural Municipal Fazenda do Carmo, 2014. Disponível em: $<$ https://www.prefeitura.sp.gov.br/cidade/secretarias/upload/meio ambiente/arq uivos/publicacoes/Volume II Planejamento all.pdf >. Acesso em: 7 abr. 2020.

SÃO PAULO. Secretaria de Infraestrutura e Meio ambiente. (2020). Programa de Uso Público. Disponível em: <http://arquivos.ambiente.sp.gov.br/fundacaoflorestal/2012/01/5 4 programa d e uso publico.pdf >. Acesso em: 5 abr. 2020.

SCHRÖETTER, S.M. et al. Percepção ambiental de alunos da escola municipal Conceição do Imbé sobre o Parque Estadual do Desengano (PED), uma experiência interdisciplinar utilizando aula de campo. Revista Científica Interdisciplinar, v. 2, p. 76-95, 2015. 
SILVA, T.N.; CAMPOS, A.C. Levantamento e identificação de impactos ambientais no Parque Municipal Carmo Bernardes, Goiânia-GO. Anais do VII Congresso Brasileiro de Gestão Ambiental. Campina Grande, PB, 2016. Disponível em: $\quad<$ https://www.ibeas.org.br/congresso/Trabalhos2016/VI030.pdf>. Acesso em: 5 abr. 2019.

SOARES, M.G., PEDROZA-JÚNIOR, H.S, MELO-JÚNIOR, M., BARROS, H.M. Extensão de Educação Ambiental na Colônia de Pesca Z-10, Itapissuma - PE (Projeto Manguezal em Nossa Casa - UNISOL 2002). Anais do I Congresso Brasileiro de Extensão Universitária. João Pessoa, PB, 2002. Disponível em: $<$ http://www.prac.ufpb.br/anais/lcbeu anais/anais/meioambiente/manguezal.pdf >. Acesso em: 24 mar. 2019.

TORRES, J.R.; FERRARI, N.; MAESTRELLI, S. R. P. Educação Ambiental crítico-transformadora no contexto escolar: teoria e prática freireana. In: LOUREIRO, C.F.B.; TORRES, J.R. (Orgs.). Educação Ambiental Dialogando com Paulo Freire. São Paulo: Cortez, p. 1-109, 2014.

VERONA, M.F. Aproximações entre o arco de Maguerez e as atividades de Educação Ambiental na escola: limites e possibilidades. 2009. 338f. Dissertação (Mestrado em Ensino de Ciências e Educação Matemática). Universidade Estadual de Londrina. Disponível em: <http://bdtd.ibict.br/vufind/Record/UEL 418d620e56ca347c20e2315db2a30570 >. Acesso em: 23 jan. 2019. 